\title{
ANALISIS PENGGUNAAN ALAT PELINDUNG DIRI DALAM PENANGANAN SAMPAH MEDIS PADA PETUGAS CLEANING SERVICE DI RSUD KABUPATEN BEKASI TAHUN 2016
}

\author{
${ }^{1}$ Farsida, ${ }^{2}$ Mirzan Zulyanda \\ 1,2 Universitas Muhammadiyah Jakarta \\ Email: farsidazaenudin@gmail.com \\ DOI : $\underline{10.24252 / k e s e h a t a n . v 12 i 1.5736 ~}$
}

\begin{abstract}
Abstrak
Alat Pelindung Diri (APD) merupakan seperangkat alat keselamatan yang digunakan oleh pekerja untuk melindungi seluruh atau sebagian tubuhnya dari kemungkinan adanya pemaparan potensi bahaya lingkungan kerja terhadap kecelakaan dan penyakit akibat kerja. Petugas cleaning service mempunyai risiko untuk terkena bahan biologi berbahaya (biohazard). Kontak dengan alat medis sekali pakai (disposable equipment) seperti jarum suntik bekas maupun selang infus bekas, serta membersihkan seluruh ruangan di rumah sakit dapat meningkatkan risiko untuk terkena penyakit infeksi. Penelitian ini bertujuan untuk mengetahui faktor yang mempengaruhi penggunaan alat pelindung diri dalam penanganan sampah medis pada petugas cleaning service di RSUD Kabupaten Bekasi Tahun 2016. Metode penelitian ini merupakan penelitian kuantitatif observasional analitik dengan menggunakan desain studi cross sectional. Sampel pada penelitian ini adalah seluruh petugas cleaning service di RSUD Kabupaten Bekasi yang berjumlah 50 orang dengan analisis bivariat menggunakan uji chisquare. Hasil penelitian menunjukkan bahwa 33 orang $(66 \%)$ responden menggunakan APD dengan lengkap, hasil analisis bivariat menunjukkan hubungan penggunaan APD dengan variabel pengetahuan ( $p$ value 0.04 dan $\mathrm{OR}=9,846)$, sikap ( $p$ value 0,002 dan $\mathrm{OR}=7,750)$, umur $(p$ value 0,352 dan OR 1,225), Pendidikan ( $p$ value 0,767 dan OR 0,498 ), dan masa kerja ( $p$ value 0,557 dan OR 0,656). Terdapat hubungan bermakna penggunaan APD dengan pengetahuan dan sikap dimana $p$ value $<0,05$ dan tidak terdapat hubungan bermakna antara penggunaan APD dengan umur, Pendidikan dan masa kerja dimana $p$ value $>0,005$.
\end{abstract}

\section{Kata Kunci: Alat Pelindung Diri; Cleaning service, Rumah Sakit}

\begin{abstract}
Personal protective equipment (PPE) is a set of safety tools used by workers to protect all or part of their body from the possibility of exposure to potential environmental hazards to work-related accidents and diseases. The cleaning service officer has the risk of being exposed to biohazard. Contact with disposable equipment such as used syringes and used infusion hoses, as well as cleaning the entire room in the hospital can increase the risk for infection. This study aims to determine the factors that affect the use of personal protective equipment in medical waste management. at the Cleaning service Officer in the District Hospital of Bekasi in 2016. Method this study is a quantitative observational analytic study using a cross sectional study design. The sample in this study were all cleaning service officers at the District Hospital. Bekasi which numbered 50 people with bivariate analysis. Results the study showed that $33(66 \%)$ respondents used PPE completely, the results of bivariate analysis showed the relationship of the use of PPE with knowledge variables ( $p$ value 0.04 and $O R=9,846$ ), attitude ( $p$ value 0.002 and
\end{abstract}


$O R=7.750$ ), age ( $p$ value 0.352 and $O R$ 1,225), Education ( $p$ value 0.767 and OR 0.498), and work period ( $p$ value 0.557 and OR 0.656). Conclusion there is a meaningful relationship between the use of PPE with knowledge and attitudes where $p$ value is $<0.05$ and there is no significant relationship between the use of PPE with age, education and years of work where the value is $>0.005$.

Keywords: Personal Protective Equipment; Cleaning Service; Hospital

\section{PENDAHULUAN}

Rumah sakit adalah industri yang bergerak di bidang pelayanan jasa kesehatan yang tujuan utamanya memberikan pelayanan jasa terhadap masyarakat sebagai usaha meningkatkan derajat kesehatan yang setinggi-tingginya. Proses pelayanan kesehatan di rumah sakit, terlihat adanya faktor-faktor penting sebagai pendukung pelayanan itu sendiri, yang selalu berkaitan satu dengan yang lainnya. Faktor-faktor tersebut meliputi pasien, tenaga kerja, mesin, lingkungan kerja, cara melakukan pekerjaan serta proses pelayanan kesehatan itu sendiri, selain memberi dampak positif, faktor tersebut juga memberikan nilai negatif terhadap semua komponen yang terlibat dalam proses pelayanan kesehatan yang berakhir dengan timbulnya kerugian (Puslitbag, 2016).

Undang-Undang Kesehatan Republik Indonesia No. 36 Tahun 2009 tentang Kesehatan, pada Pasal 164 tertulis bahwa kesehatan kerja diselenggarakan untuk melindungi pekerja agar hidup sehat dan terbebas dari gangguan kesehatan serta pengaruh buruk yang diakibatkan oleh pekerjaan di mana hal tersebut wajib diselenggarakan kesehatan kerja setiap tempat kerja. Rumah sakit merupakan tempat kerja yang mempunyai risiko bahaya kesehatan, dan mudah terjangkit penyakit (Departemen Kesehatan Republik Indonesia, 2011).

Penyakit akibat kerja di rumah sakit dapat menyerang semua tenaga kerja, baik yang medis (seperti perawat, dokter dan dokter gigi), maupun non medis seperti petugas kebersihan (cleaning service) rumah sakit. Petugas cleaning service mempunyai risiko untuk terkena bahan biologi berbahaya (biohazard). Kontak dengan alat medis sekali pakai (disposable equipment) seperti jarum suntik bekas maupun selang infus bekas, serta membersihkan seluruh ruangan di rumah sakit dapat meningkatkan risiko untuk terkena penyakit infeksi bagi petugas kebersihan (cleaning service) rumah sakit (Anies, 2011).

Pengendalian bahaya bisa dilakukan dengan berbagai cara, salah satunya adalah dengan menggunakan alat pelindung diri (APD). APD merupakan suatu alat yang dipakai untuk melindungi diri atau tubuh terhadap bahaya-bahaya kecelakaan kerja, dimana secara teknis dapat mengurangi tingkat keparahan dari kecelakaan kerja yang terjadi. Peralatan pelindung diri tidak menghilangkan atau mengurangi bahaya yang ada, peralatan ini hanya mengurangi jumlah kontak dengan bahaya dengan cara penempatan penghalang antara tenaga kerja dengan bahaya (Suma'mur, 2009) 
Dalam upaya pengelolaan sampah, setiap rumah sakit diharapkan mempunyai petugas kebersihan yang akan mengelola sampah. Karena begitu besarnya risiko yang dihadapi oleh tenaga penanganan sampah medis ini, maka perlu perlindungan bagi tenaga kerja terhadap kesehatan dan keselamatan kerja (K3) agar tidak terjadi risiko penyakit akibat kerja (PAK) dan kecelakaan akibat kerja, alat pelindung diri (APD) yang seharusnya digunakan oleh petugas penanganan sampah medis yaitu berupa helm, masker, sarung tangan, pakaian kerja khusus, sepatu khusus (Bungawati, 2011).

Setiap tempat kerja wajib menyelenggarakan kesehatan kerja dengan pendekatan pemeliharaan, peningkatan kesehatan (promotif), pencegahan penyakit, (preventif), pemulihan kesehatan (rehabilitatif) yang dilaksanakan secara menyeluruh, terpadu, dan berkesinambungan sehingga dapat terwujud derajat kesehatan masyarakat yang optimal (Wahana Lingkungan Hidup Indonesia, 2016). Menurut Peraturan Menteri Tenaga Kerja dan Transmigrasi tentang Alat Pelindung Diri (APD) tahun 2010 pasal 2 pengusaha wajib menyediakan APD bagi pekerja atau buruh di tempat kerja sesuai dengan Standar Nasional Indonesia (SNI) dan diberikan secara cuma-Cuma (Kementrian Tenaga Kerja Dan Transmigrasi RI, 2010).

Dalam profil kesehatan Indonesia, Kementerian Kesehatan RI - Direktorat Jenderal Bina Upaya Kesehatan pada tahun 2014, diungkapkan seluruh rumah sakit di Indonesia berjumlah 2.228 dengan 278.450 tempat tidur. Diperkirakan secara nasional produksi sampah rumah sakit sebesar 835.350 ton/hari. Dari gambaran tersebut dapat dibayangkan betapa besar potensi rumah sakit untuk mencemari lingkungan dan kemungkinannya menimbulkan kecelakaan serta penularan penyakit terhadap petugas yang bekerja di rumah sakit maupun masyarakat yang berada di sekitar rumah sakit (Departemen Kesehatan Republik Indonesia, 2014). Selain itu, Menurut survei yang dilakukan oleh Wahana Lingkungan Hidup Indonesia (Walhi) DKI Jakarta tentang sistem pengelolaan limbah rumah sakit di beberapa rumah sakit di Jakarta tahun 2016, rata-rata rumah sakit menghasilkan $140 \mathrm{~kg}$ sampai dengan $400 \mathrm{~kg}$ sampah medik per hari (Wahana Lingkungan Hidup Indonesia, 2016)

\section{METODOLOGI PENELITIAN}

Penelitian ini merupakan penelitian kuantitatif bersifat observasional analitik dengan desain studi cross sectional, dengan analisis bivariat menggunakan uji chi-square Populasi pada penelitian ini adalah seluruh petugas cleaning service di RSUD Kabupaten Bekasi Tahun 2016 dengan menggunakan total sampling sejumlah 50 orang. Data yang digunakan adalah data primer berupa kuesioner dan data sekunder dari management rumah sakit. 


\section{HASIL DAN PEMBAHASAN}

Tabel 1 Distribusi Karakteristik Responden, pengetahuan, Sikap dan Penggunaan APD Petugas Cleaning service di RSUD di Kabupaten Bekasi Tahun 2016

\begin{tabular}{lcc}
\hline \multicolumn{1}{c}{ Variabel } & n & \% \\
\hline Umur Responden & & \\
Remaja Akhir & 19 & 38,0 \\
Dewasa & 31 & 62,0 \\
Total & 50 & 100 \\
Pendidikan & & \\
<SMA & 18 & 36,0 \\
SMA & 32 & 64,0 \\
Total & 50 & 100 \\
Masa Kerja & & \\
$<1$ Tahun & 23 & 46,0 \\
>1 Tahun & 27 & 54,0 \\
Total & 50 & 100 \\
Penggunaan APD & & \\
Lengkap & 33 & 66,0 \\
Tidak Lengkap & 17 & 34,0 \\
Total & 50 & 100 \\
Pengetahuan & & \\
Baik & 45 & 90,0 \\
Kurang Baik & 5 & 10,0 \\
Total & 50 & 100 \\
Sikap & & \\
Positif & 30 & 60,0 \\
Negatif & 20 & 40,0 \\
Total & 50 & 100 \\
& &
\end{tabular}

Berdasarkan tabel 1 di atas dapat diketahui bahwa diketahui bahwa responden terbanyak berumur dewasa yaitu $31(62.0 \%)$ dan sebagian besar responden memiliki pendidikan SMA yaitu $32(64.0 \%)$ sedangkan pada variabel masa kerja, setengah dari responden sudah bekerja $>1$ tahun. Responden yang menggunakan APD dengan Lengkap berjumlah 33 (66.0\%), pada variabel pengetahuan $45(90.0 \%)$ responden berpengetahuan baik, sedangkan pada variabel sikap 30 (60.0\%) responden memiliki sikap positif. 
Tabel 2 Analisis Hubungan Umur, Pendidikan, Masa Kerja, Pengetahuan, dan Sikap Terhadap Penggunaan Alat Pelindung Diri pada Petugas Cleaning service di RSUD Kabupaten Bekasi Tahun 2016

\begin{tabular}{|c|c|c|c|c|}
\hline \multicolumn{5}{|c|}{ Pengggunaan APD } \\
\hline Variabel & $\begin{array}{c}\text { Lengkap } \\
\text { n (\%) }\end{array}$ & $\begin{array}{l}\text { Tidak } \\
\text { Lengkap } \\
\text { n (\%) }\end{array}$ & $\begin{array}{c}\mathrm{p}- \\
\text { value }\end{array}$ & OR $(95 \% \mathrm{CI})$ \\
\hline \multicolumn{5}{|l|}{ Umur } \\
\hline Dewasa & $21(67,7 \%)$ & $10(32,3 \%)$ & \multirow[t]{3}{*}{0,352} & \multirow[b]{2}{*}{$\begin{array}{c}1,225(0,370- \\
4,060)\end{array}$} \\
\hline $\begin{array}{l}\text { Remaja } \\
\text { Akhir }\end{array}$ & $12(63,2 \%)$ & $7(36,8 \%)$ & & \\
\hline Total & 33 & 17 & & \\
\hline \multicolumn{5}{|c|}{ Pendidikan } \\
\hline$<$ SMA & $10(55,6 \%)$ & $8(44,4 \%)$ & \multirow[b]{2}{*}{0,767} & \multirow{2}{*}{$\begin{array}{c}0,489 \\
(0,146- \\
1,636)\end{array}$} \\
\hline SMA & $23(71,9 \%)$ & $9(28,1 \%)$ & & \\
\hline Total & 33 & 17 & & \\
\hline \multicolumn{5}{|c|}{ Masa Kerja } \\
\hline$<1$ Tahun & $14(60,9 \%)$ & $9(39,1 \%)$ & \multirow{2}{*}{0,557} & \multirow{2}{*}{$\begin{array}{c}0,656(0,202- \\
2,124)\end{array}$} \\
\hline$\geq 1$ Tahun & $19(70,4 \%)$ & $8(29,6 \%)$ & & \\
\hline Total & 33 & 17 & & \\
\hline \multicolumn{5}{|c|}{ Pengetahuan } \\
\hline Baik & $32(71,1 \%)$ & $13(28,9 \%)$ & \multirow{4}{*}{0,040} & \multirow{3}{*}{$\begin{array}{c}9,846(1,003- \\
96,664)\end{array}$} \\
\hline $\begin{array}{l}\text { Kurang } \\
\text { Baik }\end{array}$ & $1(20,0 \%)$ & $4(80,0 \%)$ & & \\
\hline Total & 33 & 17 & & \\
\hline \multicolumn{4}{|l|}{ Sikap } & \\
\hline Positif & $25(83,8 \%)$ & $5(16,7 \%)$ & \multirow{2}{*}{0,002} & \multirow{2}{*}{$\begin{array}{c}7,750(2,019 \\
27,862)\end{array}$} \\
\hline Negatif & $8(40,0 \%)$ & $12(60,0 \%)$ & & \\
\hline Total & 33 & 17 & & \\
\hline
\end{tabular}

Berdasarkan tabel 2 di atas didapatkan bahwa responden yang menggunakan APD dengan lengkap pada umur dewasa 67,7 \% dan umur remaja akhir 63,2 \%, penggunaan APD yang tidak lengkap pada umur dewasa $32,3 \%$ dan umur remaja akhir 36,8\%, dengan $p$ value 0,352 >0,05 artinya tidak ada hubungan umur dengan penggunaan APD dan OR 1,225 yang artinya umur dewasa akan berpotensi menggunakan APD lengkap 1,2 kali dari pada remaja akhir. 
Pada variabel pendidikan didapatkan bahwa responden yang menggunakan APD dengan lengkap pada Pendidikan lebih rendah dari SMA 55,6 \%, pada tingkat SMA $71,9 \%$, sedangkan penggunaan APD tidak lengkap pada Pendidikan lebih rendah dari SMA 44,4 \% dan Pendidikan tingkat SMA 28,1 \%, dengan nilai $p$ value 0,767 >0,05 yang artinya tidak ada hubungan antara tingkat Pendidikan dengan penggunaan APD, dengan nilai OR 0,489 artinya Pendidikan lebih rendah dari SMA berpotensi menggunakan APD lengkap 0,5 kali dari yang berpendidikan SMA.

Pada variabel masa kerja didapatkan bahwa responden yang menggunakan APD dengan lengkap pada masa kerja $<1$ tahun $60,9 \%$, pada masa kerja $>1$ tahun $70,4 \%$, sedangkan penggunaan APD tidak lengkap pada masa kerja $<1$ tahun $39,1 \%$ dan pada masa kerja $>1$ tahun 29,6\%, dengan nilai $p$ value 0,557 >0,05 yang artinya tidak ada hubungan antara masa kerja dengan penggunaan $\mathrm{APD}$, dengan nilai OR 0,656 artinya masa kerja $<1$ tahun berpotensi 0,6 kali menggunakan APD dengan lengkap di banding yang masa kerjanya $>1$ tahun.

Pada variabel pengetahuan didapatkan bahwa responden yang menggunakan APD dengan lengkap pada pengetahuan baik $71,1 \%$, pada pengetahuan kurang baik $20,0 \%$, sedangkan penggunaan APD tidak lengkap pada pengetahuan baik $28,9 \%$ dan pada pengetahuan kurang baik $80,0 \%$, dengan nilai $p$ value $0,040<0,05$ yang artinya ada hubungan antara pengetahuan dengan penggunaan APD, dengan nilai OR 9,846 artinya pengetahuan baik berpotensi 9,8 kali menggunakan APD dengan lengkap di banding dengan pengetahuan kurang baik.

Pada variabel sikap didapatkan bahwa responden yang menggunakan APD dengan lengkap pada sikap positif $83,8 \%$, pada sikap negatif 40,0\%, senangkan penggunaan APD tidak lengkap pada sikap positif $16,7 \%$ dan pada sikap negatif $60,0 \%$, dengan nilai $p$ value $0,002<0,05$ yang artinya ada hubungan antara pengetahuan dengan penggunaan APD, dengan nilai OR 7,750 artinya sikap positif berpotensi 7,7 kali menggunakan APD dengan lengkap di banding dengan sikap negatif

\section{PEMBAHASAN}

\section{Pengetahuan}

Hasil penelitian didapatkan bahwa responden yang memiliki pengetahuan baik $71,7 \%$ menggunakan APD dengan lengkap. Hasil analisis menunjukkan bahwa adanya hubungan yang bermakna antara pengetahuan dengan penggunaan APD dengan nilai $p$ value 0.0040 , $\mathrm{OR}=9,846$, yang berarti bahwa pekerja yang mempunyai pengetahuan baik mempunyai potensi 9 kali lebih besar untuk menggunakan APD.

Berdasarkan teori safety triad, Geller mengungkapkan bahwa untuk membentuk budaya selamat terdapat tiga komponen yang saling berhubungan satu sama lain dan 
harus dicapai yaitu people (orang), behaviour (perilaku), dan environment (lingkungan) yang disebut dengan safety triad. Komponen person terdapat beberapa faktor yaitu pengetahuan, kemampuan, keterampilan, kepandaian, motivasi dan kepribadian tenaga kerja (Notoatmodjo, 2011).

Semakin tinggi tingkat pengetahuan tentang APD diharapkan memiliki perilaku yang sesuai ketika menggunakan APD. Tinggi pengetahuan responden tentang APD sejalan dengan perilaku penggunaan APD hal ini menunjukkan bahwa responden selain mengetahui juga mengaplikasikannya dalam pekerjaan sehari-hari. Menurut teori bloom menyatakan bahwa domain pengetahuan berawal dari tahu hingga domain aplikasi, domain tahu hanya mengetahui tentang prinsip-prinsip APD namun belum tentu menerapkannya alam perilaku ketika bekerja. Selain itu bloom juga menjelaskan bahwa perilaku tidak hanya dipengaruhi oleh pengetahuan saja (faktor predisposisi), akan tetapi juga dipengaruhi oleh faktor pendukung dan faktor pendorong (Notoatmodjo, 2003). Faktor pendukung meliputi ketersediaan peralatan APD di tempat praktik dapat mempengaruhi perilaku penggunaan APD pada responden. Faktor pendorong yang dapat mempengaruhi perilaku penggunaan APD pada Responden meliputi sumber daya manusia yang berinteraksi langsung dengan responden. Dalam penelitian ini terutama adalah pengawas cleaning service dan petugas kesehatan lainnya seperti perawat, dapat melakukan pengawasan terhadap penggunaan APD responden.

Penelitian ini sejalan dengan penelitian yang dilakukan oleh Melandari Tahun 2014 yang menyatakan bahwa adanya hubungan yang bermakna antara tingkat pengetahuan dengan penggunaan APD pada Cleaning Service di RSPI Sulianto Saroso (Melandari Y, Afifah E, 2014). Tingkat pengetahuan responden tentang APD sejalan dengan perilaku penggunaan APD. Hal ini menunjukkan bahwa responden selain mengetahui juga mengaplikasikannya dalam pekerjaan sehari-hari. Semakin tinggi tingkat pengetahuannya maka semakin memahami pentingnya penggunaan APD, dengan semakin rendah pengetahuan maka semakin kurang pemahaman penggunaan APD. Tingkat pengetahuan tinggi dan rendah juga dipengaruhi juga dari karakteristik respondennya.

Penelitian ini juga sejalan dengan penelitian yang dilakukan oleh Zahara, dkk. Tahun 2017 yang menyatakan bahwa adanya hubungan yang signifikan antara pengetahuan dengan Penggunaan APD pada petugas Instalasi Pemeliharaan sarana dan prasaran Rumah Sakit (Zahara Ra, Effendi Su, Khairani N, 2017).

\section{Sikap}

Didapatkan bahwa responden yang memiliki sikap positif $83,8 \%$ menggunakan APD dengan Lengkap. Hasil analisis menunjukkan adanya hubungan yang bermakna antara sikap dengan penggunaan APD dengan nilai $p$ value $0.002<0,05$ yang artinya ada 
hubungan bermakna, dengan $\mathrm{OR}=7,750$ yang artinya bahwa pekerja yang memiliki sikap yang baik akan mempunyai potensi 7 kali lebih besar untuk menggunakan APD di banding dengan yang sikap yang kurang baik. Beberapa factor yang mempengaruhi sikap seseorang karena: pengalaman, pengaruh dari orang lain, kebudayaan, Pengetahuan dan emosional seseorang. Dari penelitian ini dimana untuk variable pengetahuan responden yang baik mencapai $71,1 \%$ sehingga berkaitan dengan sikap positif yang terbentuk. Dengan sikap yang positif akan memberi dampak baik pada mutu pelayanan.

Sikap adalah reaksi atau respon seseorang terhadap stimulus atau objek tertentu, yang sudah melibatkan faktor pendapat dan emosi yang bersangkutan (Notoatmodjo, 2011). Dengan melihat pendapat di atas maka dapat dikemukakan bahwa sikap itu adalah keadaan dalam diri manusia yang menggerakkan untuk bertindak, menyertai manusia dalam keadaan-keadaan tertentu dalam menghadapi objek dan terbentuk berdasarkan pengalaman.

Mayoritas responden memiliki sikap positif terhadap pemakaian alat pelindung diri pada saat menangani sampah medis. Dengan sikap yang positif ini diharapkan tindakan pemakaian alat pelindung diri akan baik nantinya. Akan tetapi sikap yang baik belum tentu diiringi hasil yang baik pula, seperti menurut Notoadmodjo, yang menyatakan bahwa sikap belum merupakan suatu tindakan atau aktivitas, akan tetapi merupakan predisposisi tindakan suatu perilaku. Notoatmodjo mengungkapkan, bahwa struktur sikap seseorang terdiri dari komponen yang saling menunjang, yaitu komponen kognitif, afektif dan psikomotorik. Namun ketiga komponen tersebut tidak selalu saling berinteraksi untuk membentuk sikap yang utuh (total attitude). Jika individu hanya mempunyai satu atau dua komponen saja, maka sikap untuk menghasilkan perilaku yang diharapkan belum terbentuk. Hal ini menunjukkan bahwa sikap petugas kesehatan dalam melayani pasien masih perlu ditingkatkan (Notoatmodjo , 2011).

\section{KESIMPULAN}

Berdasarkan uraian di atas dapat disimpulkan bahwa $66 \%$ dari 50 responden menggunakan APD dengan lengkap. hasil analisis menunjukkan bahwa hubungan yang bermakna antara pengetahuan dan sikap terhadap penggunaan APD. Pengetahuan berpotensi 9 kali lebih besar untuk menggunakan APD secara baik, dan sikap yang baik berpotensi 7 kali lebih besar untuk menggunakan APD dengan baik. Sedangkan pada variabel umur, pendidikan dan masa kerja tidak terdapat hubungan yang bermakna dengan penggunaan APD. Semakin baik pengetahuan dan sikap positif, maka semakin patuh terhadap penggunaan APD, Adapun faktor yang mempengaruhi penggunaan APD selain faktor pendukung, pendorong dan juga karakteristik responden. 
Diharapkan kepada pihak rumah sakit untuk memberikan edukasi dan pelatihan kepada seluruh pegawai yang ada di RSUD Kota Bekasi Tahun 2016 mengenai Pentingnya penggunaan APD secara baik.

\section{DAFTAR PUSTAKA}

Anies. (2011). Penyakit Akibat Kerja. Jakarta: Elex Media Komputindo.

Bungawati. A. (2011). Penerapan Kesehatan dan Keselamatan Kerja pada Petugas Penanganan Sampah di Rumah Sakit Kota Palu. Promotif, 1(1).

Departemen Kesehatan Republik Indonesia. (2011). Keputusan Menteri Kesehatan Ri No 1087/Menkes/Sk/Viii/2010.

Departemen Kesehatan Republik Indonesia. (2014). Direktorat Jenderal Bina Upaya Kesehatan. Jakarta.

Fahmi I. (2016). Perilaku Organisasi (Teori, Aplikasi dan Kasus). Bandung: Alfabeta.

Febrianty D. (2012). Gambaran Penggunaan Alat Pelindung Diri Oleh Bidan di Desa Pada Waktu Melakukan Pertolongan Persalinan di rumah dan Faktor-Faktor Yang Mempengaruhi di Wilayah Kerja Dinas Kesehatan Kabupaten Balangan.

Harlan A. N \& Paskarini I. (2014). Faktor Yang Berhubungan dengan Perilaku Penggunaan Apd Pada Petugas Laboratorium Rumah Sakit Phe Surabaya. Indonesan J Enviroment. 1 (1), 107-9.

Hendra Y. M. U. T. S. (2011). Praktik Pemakaian Alat Pelindung Diri (Apd) Pada Radiografer Di Instalasi Radiologi 4 Rumah Sakit Di Kota Semarang. Jurnal Kesehatan Masyarakat Indonesia. 7 (1), 9-14.

Kementrian Tenaga Kerja dan Transmigrasi Republik Indonesia. (2010). Peraturan Menteri Tenaga Kerja dan Transmigrasi Republik Indonesia No. Per.08/Men/Vii/2010 Tentang Alat Pelindung Diri.

Khamdani F. (2009). Hubungan Antara Pengetahuan dan Sikap dengan Pemakaian Alat Pelindung Diri Pestisida Semprot Pada Petani di Desa Angkatan Kidul Pati Tahun 2009.

Melandari Y, Afifah E. (2014). Hubungan Tingkat Pengetahuan dengan Kepatuhan Menggunakan Alat Pelindung Diri Pada Cleaning service di Rspi Sulianti Saroso.

Puslitbag. (2016). Ikm Fk Ugm Dan Program S2 Hiperkes Ugm. Puslitbag Ikm Fk Ugm

Dan Program S2 Hiperkes Ugm. Yogyakarta: Fakultas Kedokteran Universitas Gajah Mada.

Septiningsih, E. (2017). Penguatan Masa Kerja dalam Meningkatkan Kepatuhan Penggunaan Alat Pelindung Diri Pada Petugas Kebersihan. 2017;

Soekidjo Notoatmodjo. (2003). Pendidikan dan Perilaku Kesehatan. Jakarta: Rineka Cipta. Soekidjo Notoatmodjo. (2011). Pendidikan dan Perilaku Kesehatan. Jakarta: Rineka Cipta.

Suma'mur. (2009). Higiene Perusahaan dan Kesehatan Kerja (Hiperkes). Jakarta: Sagung Seto.

Veronika T. (2015). Gambaran Pengetahuan, Sikap Dan Tindakan Terhadap Pemakaian Alat Pelindung Diri Dalam Penanganan Sampah Medis Pada Petugas Cleaning service Di Rsud Dr. Pirngadi Medan. 
Wahana Lingkungan Hidup Indonesia (Walhi) DKI Jakarta. (2016). Survei Sistem Pengelolaan Limbah Rumah Sakit. https://Walhi.Or.Id/

Wekoyla. (2012). Hubungan Pengetahuan, Sikap, Pendidikan, dan Masa Kerja Bidan Terhadap Perilaku Penggunaan Alat Pelindung Diri pada Tindakan Pertolongan Persalinan di Rumah Sakit Umum Provinsi Sulawesi Tenggara dan Rumah Sakit Umum Kota Kendari.

Zahara Ra., Effendi Su., Khairani N. (2017). Kepatuhan Menggunakan Alat Pelindung Diri (APD) Ditinjau dari Pengetahuan dan Perilaku pada Petugas Instalasi Pemeliharaan Sarana dan Prasarana Rumah Sakit ( Ipsrs ), 2(2), 153-8. 